\title{
Effect of sensory and motor electrical stimulation in vascular endothelial growth factor expression of muscle and skin in full-thickness wound
}

\author{
Mohammad Reza Asadi, MSc; ${ }^{1}$ Giti Torkaman, PhD; ${ }^{1 *}$ Mehdi Hedayati, PhD $^{\mathbf{2}}$ \\ ${ }^{1}$ Physical Therapy Department, Faculty of Medical Sciences, Tarbiat Modares University, Tehran, Islamic Republic of \\ Iran; ${ }^{2}$ Obesity Research Center, Research Institute for Endocrine Sciences, Shahid Beheshti University of Medical \\ Sciences, Tehran, Islamic Republic of Iran
}

\begin{abstract}
Vascular endothelial growth factor (VEGF) is important in improving wound healing. We evaluated the effect of sensory (direct current, 600 microamperes) and motor (monophasic current, pulse duration 300 microseconds, $100 \mathrm{~Hz}, 2.5-3.0 \mathrm{~mA}$ ) intensities of cathodal electrical stimulation (ES) current to release VEGF in muscle and skin in the wound site. We randomly assigned 48 male Sprague-Dawley rats into one control and two experimental groups (sensory and motor ESs). A fullthickness skin incision was made on each animal's dorsal region. The experimental groups received ES for $1 \mathrm{~h} /$ day every other day. In the control group, no current was applied. VEGF expression was measured in muscle and skin on the third and seventh days after surgical incision. Our outcomes demonstrated that no difference was found in the VEGF levels among groups on the third day. However, on the seventh day, the skin VEGF levels in the sensory group were significantly higher than those levels of the other groups $(p<0.05)$. No difference was found in the muscle VEGF levels on the third and seventh days. The results showed that sensory ES increases the release of more VEGF in skin. This mechanism may be one through which a sensory type of current is more effective in promoting wound healing.
\end{abstract}

Key words: cathode, direct current, electrical stimulation, fullthickness wound, monophasic current, muscle, rat, skin, VEGF, wound healing.

\section{INTRODUCTION}

Wound healing is characterized by a complex series of biological processes in response to injuries that ulti- mately cause tissue formation, reepithelialization, and scar formation. Angiogenesis is an integral part of this sequence of events and occurs during the proliferative phase of wound healing. It is characterized by new vessel formation and vascular hyperpermeability that improve tissue oxygenation and nutrient delivery and promote cellular and matrix deposition in the wound [1]. A potent direct angiogenic factor is the vascular endothelial growth factor (VEGF), which stimulates migration, proliferation, and/or tube formation of endothelial cells [2-4]. Direct and indirect evidence implicates that VEGF is significant in wound healing immediately after injury and stimulates wound healing through multiple mechanisms, including collagen deposition, angiogenesis, and epithelialization [2,5]. VEGF level in the wound site was observed as markedly elevated immediately after injury. Maximal VEGF level is between the third and seventh

Abbreviations: $\mathrm{ANOVA}=$ analysis of variance, $\mathrm{DC}=$ direct current, ELISA = enzyme-linked immunosorbent assay, ES = electrical stimulation, LIDC $=$ low-intensity DC, LVES $=$ lowvoltage $\mathrm{ES}, \mathrm{SEM}=$ standard error of the mean, $\mathrm{VEGF}=$ vascular endothelial growth factor.

*Address all correspondence to Giti Torkaman, PhD; Physical Therapy Department, Faculty of Medical Sciences, Tarbiat Modares University, Tehran, Islamic Republic of Iran 1411713116; +98-21-82884509; fax: +98-21-88006544.

Email: torkamg@modares.ac.ir

DOI:10.1682/JRRD.2009.11.0182 
days after full-thickness wounding, coincident with early stage of the proliferation phase of wound healing [2]. During this period, VEGF upregulated to promote vascular dilation, permeability, migration, and proliferation of endothelial cells [6]. The elevated synthesis declined to a basal level in 7 to 14 days after skin injury [2]. Capillary growth in the wound alleviates tissue hypoxia and metabolic deficiencies [1-2], which may subsequently promote wound closure and better formation of granulation tissue and their remodeling [1]. However, no in vivo studies were found in the literature bearing directly on the effects of VEGF expression on different phases of wound healing.

Evidence exists that electrical stimulation (ES) increases the release of VEGF in the muscle and wound site [7-12]. Thus, recruitment of muscle by ES may be a way to facilitate angiogenesis in wound healing. Hang et al. reported the VEGF gene expression is unregulated in rat skeletal muscle [7]. They stimulated muscle electrically at $10 \mathrm{~Hz}$ using $300 \mathrm{~ms}$ square waves at voltages that maximized contraction on palpation for up to 21 days. Nagasaka et al. reported the VEGF protein was significantly increased by low-voltage ES (LVES) in rat skeletal muscle that was stimulated continuously for 5 days at $50 \mathrm{~Hz}$, with unipolar square waves at stimulus strength below threshold muscle contraction [8]. In this study, the active electrode had negative polarity and was implanted onto the tibialis anterior muscle. In addition, some studies demonstrated that ES increased the release of VEGF in rat skeletal muscle, both when ES caused muscle contraction [1011] and following subthreshold stimulation, which did not induce contraction [9]. Morris et al. applied squarewave pulsed direct current (DC) ES to ischemic wounds in the ear of rabbits for either 1, 2, or 3 weeks (10 rabbits were assigned in two experimental groups, A and B) [12]. Both groups received amplitude of $11 \mathrm{~mA}$, with an interpulse interval of $40 \mathrm{~ms}$, but pulse width was set at $110 \mu \mathrm{s}$ in group A and $5 \mu \mathrm{s}$ in group B. They found that VEGF level was significantly higher for the stimulation pattern in group A (110 $\mu$ s pulse width) than in group B ( $5 \mu$ s pulse width) on the fourteenth day following injury. Their results implied that the ES pattern in group A might be more effective at promoting angiogenesis. Zhao et al. reported that applied electric fields of small physiological magnitude directly stimulate VEGF production by endothelial cells in culture without the presence of any other cell types [13].
In wound healing, VEGF is produced by endothelial cells, fibroblasts, platelets, neutrophils, keratinocytes, and macrophages [2]. In vitro studies have reported that fibroblasts, neutrophils, and keratinocytes migrated toward cathode (negative polarity) in electric fields [14]. Talebi et al. showed that the cathodal ES increased the number of macrophages and fibroblast cells as compared with that in the control [15]. Therefore, applying the cathodal ES on the wound site apparently increases the release of more VEGF.

The low-intensity DC (LIDC) within the range of 200 to $800 \mu \mathrm{A}$ effectively promotes and accelerates wound healing [16]. The intensities of $>1 \mathrm{~mA}$ have not been studied, in either continuous or pulsed DC [16]. In addition, the effect of ES on releasing VEGF in an acute wound site, as one of the most important mechanisms of effectiveness of ES on wound healing, has not been studied. One cannot fully define the optimal treatment and stimulation parameters without clearly understanding the basic mechanisms of ES in promoting wound healing.

We conducted this study to investigate the role of sensory $(600 \mu \mathrm{A})$ and motor (threshold of contraction) intensities of cathodal current on releasing VEGF in wound healing. Specifically, we designed the study to answer the following two questions:

1. Does externally applied cathodal ES influence the release of VEGF in the wound site?

2. Which intensities of ES (sensory or motor) have better effects to release VEGF in the wound site?

\section{MATERIALS AND METHODS}

\section{Animals}

In this investigation, we used 48 healthy male SpragueDawley rats (Razi Vaccine and Serum Research Institute; Karaj, Tehran, Iran) weighing 250 to $300 \mathrm{~g}$. The animals were maintained in special cages according to the controlled conditions in the experimental guidelines of Tarbiat Modares University. Animals could access food without any limitation until 12 hours before the surgery.

\section{Wounding and Treatment Protocol}

After weighing the animals, we anesthetized them using a mixture of xylazine hydrochloride $(20 \mathrm{mg} / \mathrm{mL})$ and ketamine hydrochloride $(100 \mathrm{mg} / \mathrm{mL}$, Alfasan; Woerden, the Netherlands) (xylazine: ketamine ratio of 1:9 mL and dose of $1 \mathrm{~mL} / \mathrm{kg}$ ). The hairs on the middle of each 
rat's back were shaved, and the area was cleaned with Betadine antiseptic solution (Purdue Products L.P.; Stanford, Connecticut). Following the sterilization, we made a $2.5 \mathrm{~cm}$ longitudinal full-thickness incision, in the craniocaudal direction, at a distance of $1 \mathrm{~cm}$ from the spine on the right side of the paravertebral region.

We divided animals randomly into one control and two experimental groups (sensory and motor ESs). Each group included 16 animals consisting of 8 rats that were studied for 3 days and 8 rats that were studied for 7 days. Treatment began 24 hours after injury. Carbon rubberized electrodes were placed on a sterile gauze moistened with normal saline solution. An active treatment electrode $(1 \times$ $3 \mathrm{~cm}$ ) was placed on the incision wound site, and a passive indifferent electrode $(2 \times 4 \mathrm{~cm})$ was placed on the opposite side of the paravertebral region, at the highest part of the back (Figure 1). To prevent electrode displacement, we tied the electrodes tightly using straps and constrained animal movement using the restrainer. In both the experimental groups, the polarity of the active treatment electrode was negative (cathode) during applied protocol. In the sensory ES group, we applied microamperage DC ES with an intensity of $600 \mu \mathrm{A}$, for $1 \mathrm{~h} /$ day, every other day, for 3 or 7 days. In the motor ES group, we applied monophasic pulsed current with an intensity enough to elicit a visible minimum contraction (about 2.5-3.0 mA), pulse duration $300 \mu \mathrm{s}$, frequency $100 \mathrm{~Hz}$, for $1 \mathrm{~h} /$ day, every other day, for 3 or 7 days. These ES parameters

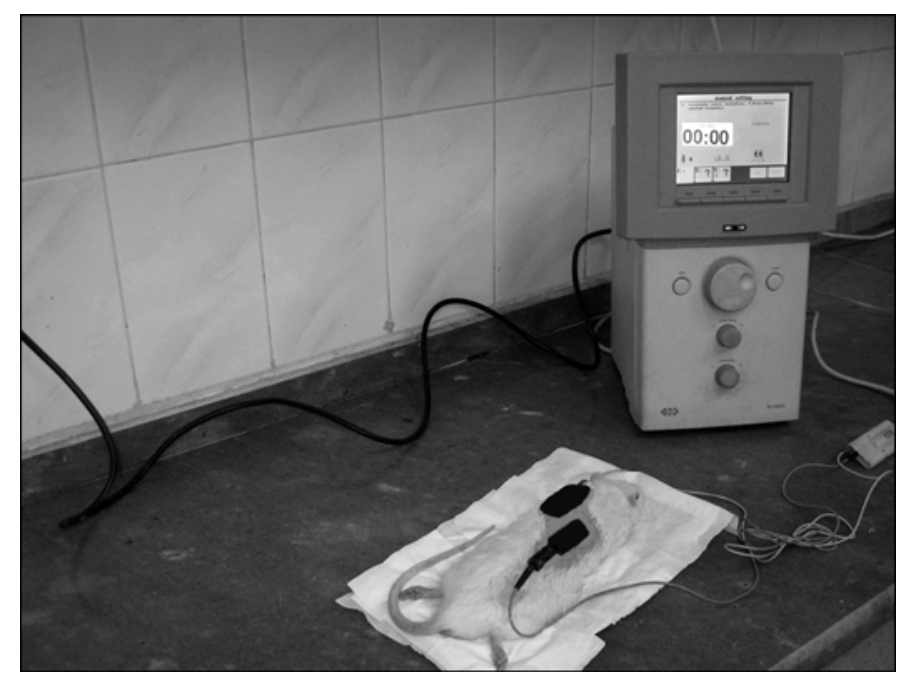

Figure 1.

Electrode positions before restrainer was used. Right electrode was active $(1 \times 3 \mathrm{~cm})$, and left electrode was passive indifferent $(2 \times 4 \mathrm{~cm})$. have been used in many other studies [15,17-19]. The ES device used in this study was the BTL-5000 series (BTL Industries Ltd; Hertfordshire, United Kingdom). In the control group, we similarly placed electrodes on the wound site but applied no current.

\section{Tissue Preparation and VEGF Level Determination}

On the third and seventh days postinjury, eight rats in each group were euthanized by chloroform inspiration and wound strips were removed along the incision, including $3 \mathrm{~mm}$ from the edges, and were used as tissue samples for examining skin VEGF protein. In addition, after removing the wound strips, we excised muscle tissue under the wound area site in a rectangular shape $(0.5 \times$ $1.0 \mathrm{~cm}$, respectively, as width and length in the same direction of wound incision) to measure the muscle VEGF protein.

Tissue samples were homogenized in phosphatebuffered saline containing antiprotease (phenylmethanesulfonyl fluoride, ethylenediaminetetraacetic acid, aprotinin, for each $100 \mathrm{mg}$ of tissue, $1 \mathrm{~mL}$ buffer). The homogenates were centrifuged at 12,000 revolutions per minute for $15 \mathrm{~min}$ at $4{ }^{\circ} \mathrm{C}$. The supernatant was collected and stored at $-80^{\circ} \mathrm{C}$ until used. VEGF was determined with an enzyme-linked immunosorbent assay (ELISA) kit (R\&D Systems, Inc; Minneapolis, Minnesota). Standards or samples $(50 \mu \mathrm{L})$ were pipetted into each antibodycoated well containing $50 \mu \mathrm{L}$ assay diluents and incubated for $2 \mathrm{~h}$ at room temperature. The wells were washed five times with wash buffer, and then $100 \mu \mathrm{L}$ of VEGF conjugate were added to each well. Microplates were again incubated for $2 \mathrm{~h}$ at room temperature. After the five washings of the wells, solutions of $100 \mu \mathrm{L}$ substrate chromogen were added. The microplates were incubated for $30 \mathrm{~min}$ at room temperature. Optical density was read in a microplate ELISA reader (Sunrise Model Co; Vienna, Austria) at the wavelength of $450 \mathrm{~nm}$. The tissue sample concentration was calculated from the standard curve and normalized by the weight of the skin.

\section{Statistical Analysis}

The Kolmogorov-Smirnov test demonstrated that the VEGF levels were normally distributed in all groups $(p>$ 0.05 ). We used one-way analysis of variance (ANOVA) and Tukey test to evaluate the differences of VEGF protein on the third and seventh days between experimental and control groups. We considered $p<0.05$ statistically 
significant. We used SPSS statistical software, version 16.0 (SPSS Inc; Chicago, Illinois), for the analysis.

\section{RESULTS}

\section{VEGF Protein Level in Skin Wound Tissue}

The levels of VEGF protein in skin wound tissue of the different groups on the third and seventh days postinjury are shown in Table 1. On the third day postinjury, the VEGF levels (mean \pm standard error of the mean [SEM]) in the sensory, motor, and control groups were $3.64 \pm 0.72,3.28 \pm 0.46$, and $3.20 \pm 0.65 \mathrm{pg} / \mathrm{mg}$, respectively (Figure 2). Although the VEGF protein levels in the sensory group were higher than those levels in the motor and control groups on the third day, this difference was not significant $(p=0.8)$.

On the seventh day postinjury, the VEGF levels (mean $\pm \mathrm{SEM}$ ) in the sensory, motor, and control groups were $4.43 \pm 0.97,1.74 \pm 0.59$, and $1.14 \pm 0.46 \mathrm{pg} / \mathrm{mg}$, respectively (Figure 2). ANOVA revealed significant difference among the groups on the seventh day $(p=$ 0.01). Tukey test demonstrated that the VEGF protein levels in the sensory group were significantly higher than those levels in the motor and control groups on the seventh day ( $p=0.03$ and $p=0.01$, respectively), but differences between the motor and control groups were not significant $(p=0.8)$.

\section{VEGF Protein Level in Muscle Tissue}

The levels of VEGF protein in muscle tissue from different groups on the third and seventh days postinjury are presented in Table 2. On the third day postinjury, the VEGF levels (mean \pm SEM) in the sensory, motor, and control groups were $0.66 \pm 0.13,0.67 \pm 0.15$, and $0.86 \pm$

Table 1.

Skin vascular endothelial growth factor (VEGF) on third and seventh days after incision as mean \pm standard error of the mean.

\begin{tabular}{lcc}
\hline \multirow{2}{*}{ Group } & \multicolumn{2}{c}{ VEGF (pg/mg) } \\
\cline { 2 - 3 } & Day 3 & Day 7 \\
\hline Sensory & $3.64 \pm 0.72$ & $4.43 \pm 0.97^{*}$ \\
Motor & $3.28 \pm 0.46$ & $1.74 \pm 0.59$ \\
Control & $3.20 \pm 0.65$ & $1.14 \pm 0.46$ \\
\hline Fignificantly different than motor and control groups; $p<0.05$. \\
\hline
\end{tabular}

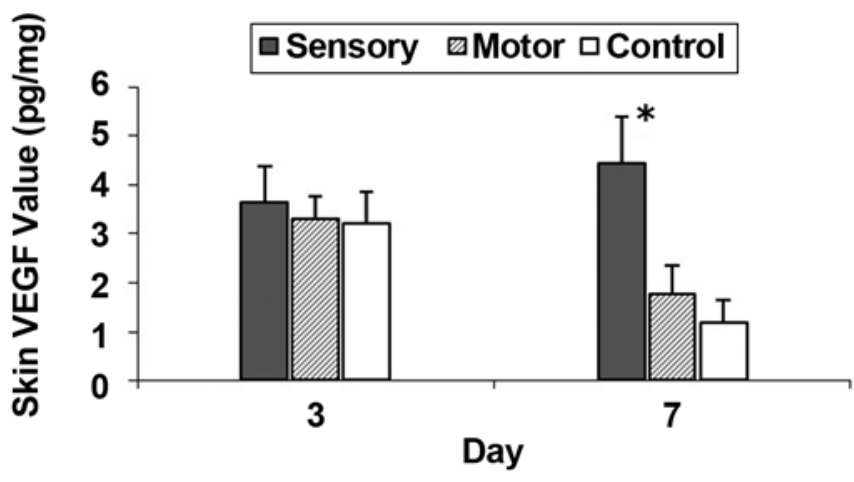

Figure 2.

Skin vascular endothelial growth factor (VEGF) on third and seventh days after incision. Levels are expressed as mean \pm standard error of the mean. ${ }^{*}$ Significant difference related to control and motor groups.

$0.14 \mathrm{pg} / \mathrm{mg}$, respectively (Figure 3). ANOVA revealed no differences among groups on the third day $(p=0.5)$.

On the seventh day postinjury, the VEGF levels (mean $\pm \mathrm{SEM}$ ) in the sensory, motor, and control groups were $0.34 \pm 0.08,0.29 \pm 0.04$, and $0.35 \pm 0.05 \mathrm{pg} / \mathrm{mg}$, respectively (Figure 3). ANOVA revealed no differences among groups on seventh day $(p=0.8)$.

\section{DISCUSSION}

Although many clinical articles support the use of ES for wound healing [20-25], the mechanism by which ES induces wound healing is not well known. Many evidences implicate VEGF as a significant factor in wound healing immediately after injury [2,5-6]. In this study, we determined the effect of ES on the release of VEGF in the incision wound site.

In full-thickness wounds, maximal VEGF protein is found between the third and seventh days after wounding,

Table 2.

Muscle vascular endothelial growth factor (VEGF) on third and seventh days after incision as mean \pm standard error of the mean.

\begin{tabular}{lcc}
\hline \multirow{2}{*}{ Group } & \multicolumn{2}{c}{ VEGF (pg/mg) } \\
\cline { 2 - 3 } & Day 3 & Day 7 \\
\hline Sensory & $0.66 \pm 0.13$ & $0.34 \pm 0.08$ \\
Motor & $0.67 \pm 0.15$ & $0.29 \pm 0.04$ \\
Control & $0.86 \pm 0.14$ & $0.35 \pm 0.05$ \\
\hline \hline
\end{tabular}




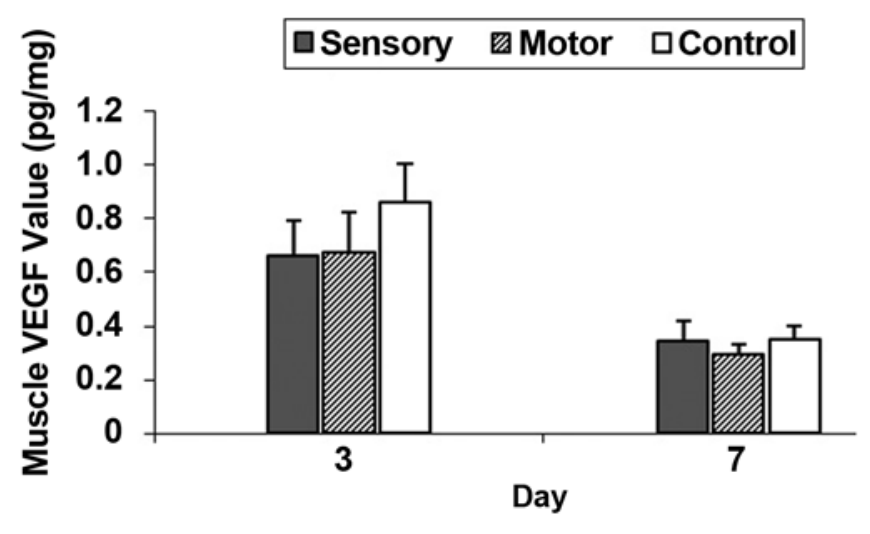

Figure 3.

Muscle vascular endothelial growth factor (VEGF) on third and seventh days after incision. Levels are expressed as mean \pm standard error of the mean.

coincident with the early stages of angiogenesis [2]. In the present study, we demonstrated that the pattern of VEGF expression in injured skin was similar in the motor and control groups. In both groups, skin VEGF level reached its peak on the third day postinjury and decreased on the seventh day. However, in the sensory group, skin VEGF level reached its peak on the seventh day postinjury. The level of skin VEGF protein in the sensory group was significantly higher than the level in the motor and control groups by the seventh day $(p<0.05)$.

Morris et al. reported that application of pulsed DC ES with $110 \mu$ s pulse width significantly increased VEGF level on the fourteenth day compared with application of pulsed DC ES with $5 \mu$ s pulse width [12]. They applied ES to ischemic full-thickness wounds in the ears of rabbits. The mechanisms by which ES increases the release of VEGF in the wound site are still not well known.

In wound healing, VEGF is produced by endothelial cells, fibroblasts, platelets, neutrophils, keratinocytes, and macrophages [2]. In vitro studies have reported that fibroblasts, neutrophils, and keratinocytes migrated toward cathode (negative polarity) in electric fields [14]. Talebi et al. showed that the cathodal ES in the experimental group increased the number of macrophages and fibroblast cells compared with that in the control group [15]. In addition, they claimed that LIDC may resemble the natural electrical field current created following injury, thus it can enhance galvanotaxis (directional migration of various types of cells) [26].

Therefore, the sensory ES compared with motor ES can facilitate better cell migration (such as neutrophils, macrophages, fibroblasts, and keratinocytes) to the wound site; thus, it increases the release of more VEGF in the wound site as compared with motor-intensity ES and control groups. The increase of skin VEGF level by sensory ES on the third and seventh days postinjury concurs with early stages of angiogenesis; thus, sensory ES may be more effective at promoting angiogenesis in wound healing.

Evidence exists that ES increases the release of VEGF in muscle [7-11]. Hang et al. reported that the VEGF gene expression is upregulated in rat skeletal muscle that was stimulated electrically at $10 \mathrm{~Hz}$ using $300 \mathrm{~ms}$ square waves at voltages that maximized contraction on palpation for up to 21 days [7]. Nagasaka et al. reported that the VEGF protein was significantly increased by LVES in rat skeletal muscle that was stimulated continuously for 5 days at $50 \mathrm{~Hz}$, with unipolar square waves at stimulus strength below threshold muscle contraction [8]. In their study, the active electrode had negative polarity and was implanted onto the tibialis anterior muscle. Kanno et al. reported that ES increased VEGF and blood flow when cultured skeletal muscle cells were electrically stimulated at a voltage that did not cause contraction [9].

In the present study, we observed no significant increase in levels of VEGF protein in muscle under the wound site in any groups on the third and seventh days postinjury. Conflicting results may be explained by the difference in duration of application of ES and by areas of stimulation. In the previous studies, muscle was stimulated continuously for 5 or 21 days, but in the present study, muscle was stimulated for $1 \mathrm{~h} /$ day, every other day, for 3 or 7 days. In addition, in previous studies, muscle was stimulated in ischemic conditions $[7,8]$, but in this study, muscle was stimulated in the condition of normal blood perfusion. Therefore, neither the sensory nor the motor ES (parameters used in this study) apparently increases the release of VEGF by muscle cells during full-thickness wound healing. Further work is needed to determine the relationship between VEGF expression after sensory and motor ES and its angiogenesis effect during wound healing. 


\section{CONCLUSIONS}

In summary, this study demonstrated more expression of skin VEGF on the third and seventh days after application of sensory ES. Using sensory or motor ES could not change the expression of muscle VEGF in the wound site. The effect of sensory ES to release more VEGF may be one through which sensory ES is more effective in promoting wound healing.

\section{ACKNOWLEDGMENTS}

\section{Author Contributions:}

Study concept and design: G. Torkaman, M. R. Asadi.

Acquisition of data: M. R. Asadi, G. Torkaman, M. Hedayati.

Analysis and interpretation of data: G. Torkaman, M. R. Asadi.

Drafting of manuscript: G. Torkaman, M. R. Asadi, M. Hedayati.

Critical revision of manuscript for important intellectual content:

G. Torkaman, M. R. Asadi, M. Hedayati.

Statistical analysis: M. R. Asadi, G. Torkaman.

Obtained funding: G. Torkaman.

Financial Disclosures: The authors have declared that no competing interests exist.

Funding/Support: This material was based on work supported by grant 87040798 of Iran National Science Foundation resources and facilities of Tarbiat Modares University, Tehran, Islamic Republic of Iran.

Institutional Review: The Ethical Commission of Tarbiat Modares

University approved the study.

\section{REFERENCES}

1. Eming SA, Brachvogel B, Odorisio T, Koch M. Regulation of angiogenesis: Wound healing as a model. Prog Histochem Cytochem. 2007;42(3):115-70. [PMID: 17980716] DOI:10.1016/j.proghi.2007.06.001

2. Bao P, Kodra A, Tomic-Canic M, Golinko MS, Ehrlich HP, Brem $\mathrm{H}$. The role of vascular endothelial growth factor in wound healing. J Surg Res. 2009;153(2):347-58.

[PMID: 19027922]

DOI:10.1016/j.jss.2008.04.023

3. Bates DO, Jones RO. The role of vascular endothelial growth factor in wound healing. Int J Low Extrem Wounds. 2003;2(2):107-20. [PMID: 15866835]

DOI: $10.1177 / 1534734603256626$

4. Thomas KA. Vascular endothelial growth factor, a potent and selective angiogenic agent. J Biol Chem. 1996;271(2): 603-6. [PMID: 8557658]

5. Stojadinovic O, Kodra A, Golinko MS, Tomic-Canic M, Brem H. A novel non-angiogenic mechanism of VEGF:
Stimulation of keratinocyte and fibroblast migration [abstract]. Wound Repair Regen. 2007;15:A30.

6. Nissen NN, Polverini PJ, Koch AE, Volin MV, Gamelli RL, DiPietro LA. Vascular endothelial growth factor mediates angiogenic activity during the proliferative phase of wound healing. Am J Pathol. 1998;152(6):1445-52.

[PMID: 9626049]

7. Hang J, Kong L, Gu JW, Adair TH. VEGF gene expression is upregulated in electrically stimulated rat skeletal muscle. Am J Physiol. 1995;269(5 Pt 2):H1827-31.

[PMID: 7503283]

8. Nagasaka M, Kohzuki M, Fujii T, Kanno S, Kawamura T, Onodera H, Itoyama Y, Ichie M, Sato Y. Effect of low-voltage electrical stimulation on angiogenic growth factors in ischaemic rat skeletal muscle. Clin Exp Pharmacol Physiol. 2006;33(7):623-27. [PMID: 16789930] DOI:10.1111/j.1440-1681.2006.04417.x

9. Kanno S, Oda N, Abe M, Saito S, Hori K, Handa Y, Tabayashi K, Sato Y. Establishment of a simple and practical procedure applicable to therapeutic angiogenesis. Circulation. 1999;99(20):2682-87. [PMID: 10338463]

10. Annex BH, Torgan CE, Lin P, Taylor DA, Thompson MA, Peters KG, Kraus WE. Induction and maintenance of increased VEGF protein by chronic motor nerve stimulation in skeletal muscle. Am J Physiol. 1998;274(3 Pt 2):H860-67. [PMID: 9530197]

11. Amaral SL, Linderman JR, Morse MM, Greene AS. Angiogenesis induced by electrical stimulation is mediated by angiotensin II and VEGF. Microcirculation. 2001;8(1): 57-67. [PMID: 11296854]

12. Morris KA, McGee MF, Jasper JJ, Bogie KM. Evaluation of electrical stimulation for ischemic wound therapy: A feasibility study using the lapine wound model. Arch Dermatol Res. 2009;301(4):323-27. [PMID: 19050907] DOI:10.1007/s00403-008-0918-2

13. Zhao M, Bai H, Wang E, Forrester JV, McCaig CD. Electrical stimulation directly induces preangiogenic responses in vascular endothelial cells by signaling through VEGF receptors. J Cell Sci. 2004;117(Pt 3):397-405. [PMID: 14679307]

14. Kloth LC. Electrical stimulation for wound healing: A review of evidence from in vitro studies, animal experiments, and clinical trials. Int J Low Extrem Wounds. 2005; 4(1):23-44. [PMID: 15860450] DOI: $10.1177 / 1534734605275733$

15. Talebi G, Torkaman G, Firoozabadi M, Shariat S. Effect of anodal and cathodal micro-amperage direct current on the skin wound healing: A biomechanical and histological study. J Biomech. 2007;40(S2):S665.

16. Balakatounis KC, Angoules AG. Low-intensity electrical stimulation in wound healing: Review of the efficacy of 
externally applied currents resembling the current of injury. Eplasty. 2008;8:e28. [PMID: 18552975]

17. Taşkan I, Ozyazgan I, Tercan M, Kardaş HY, Balkanli S, Saraymen R, Zorlu U, Ozügül Y. A comparative study of the effect of ultrasound and electrostimulation on wound healing in rats. Plast Reconstr Surg. 1997;100(4):966-72. [PMID: 9290665] DOI:10.1097/00006534-199709001-00020

18. Reger SI, Hyodo A, Negami S, Kambic HE, Sahgal V. Experimental wound healing with electrical stimulation. Artif Organs. 1999;23(5):460-62. [PMID: 10378943] DOI:10.1046/j.1525-1594.1999.06365.x

19. Mehmandoust FG, Torkaman G, Firoozabadi M, Talebi G. Anodal and cathodal pulsed electrical stimulation on skin wound healing in guinea pigs. J Rehabil Res Dev. 2007; 44(4):611-18. [PMID: 18247258]

DOI:10.1682/JRRD.2007.01.0007

20. Vodovnik L, Karba R. Treatment of chronic wounds by means of electric and electromagnetic field. Part 1. Literature review. Med Biol Eng Comput. 1992;30(3):257-66.

[PMID: 1453797] DOI:10.1007/BF02446963

21. Mertz P, Davis S, Cazzaniga A, Cheng K, Reich JD, Eaglstein WH. Electrical stimulation: Acceleration of soft tissue repair by varying the polarity. Wounds. 1993;5(3):153-59.

22. Karba R, Semrov D, Vodovnik L, Benko H, Savrin R. DC electrical stimulation for chronic wound healing enhancement. Part 1. Clinical study and determination of electrical field distribution in the numerical wound model. Bioelectrochem Bioenerg. 1997;43(2):256-70. DOI:10.1016/S0302-4598(96)05192-6
23. Alvarez OM, Mertz PM, Smerbeck RV, Eaglstein WH. The healing of superficial skin wounds is stimulated by external electrical current. J Invest Dermatol. 1983;81(2):144-48. [PMID: 6308102] DOI:10.1111/1523-1747.ep12543498

24. Brown M, Gogia PP. Effects of high voltage stimulation on cutaneous wound healing in rabbits. Phys Ther. 1987;67(5): 662-67. [PMID: 3495010]

25. Brown M, McDonnell MK, Menton DN. Electrical stimulation effects on cutaneous wound healing in rabbit. A followup study. Phys Ther. 1988;68(6):955-60. [PMID: 3259701]

26. Kloth LC, McCulloch JM. Promotion of wound healing with electrical stimulation. Adv Wound Care. 1996;9(5): 42-45. [PMID: 9069747]

Submitted for publication November 11, 2009. Accepted in revised form May 13, 2010.

This article and any supplementary material should be cited as follows:

Asadi MR, Torkaman G, Hedayati M. Effect of sensory and motor electrical stimulation in vascular endothelial growth factor expression of muscle and skin in fullthickness wound. J Rehabil Res Dev. 2011;48(3):195-202. DOI:10.1682/JRRD.2009.11.0182

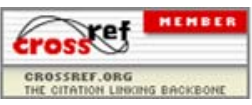


